\title{
MECENAZGO Y LITERATURA MEDIEVAL
}

\author{
Victoria Cirlot
}

A lo largo del siglo XII tuvo lugar uno de los fenómenos más significativos para la evolución y el destino del Occidente europeo, pues surgió una literatura escrita en lengua vulgar que, en menos de cien años, habría de configurar *obras maestras» en cada uno de los distintos génetos ${ }^{1}$. Los estudiosos se han esforzado por ofrecer una explicación a este suceso literario y una de las perspectivas de análisis ha consistido en ubicar las obras y fijar el ambiente social, cultural y político que vivieron los escritores de la Edad Media. Ha sido sin duda una tarea ardua debido a la escasez documental, pero un persistente y tenaz espíritu arqueológico ha logrado en muchas ocasiones «reconstruirs la circunstancia en que se desarrollaron los cantares de gesta, los romans o los poemas líricos. Modernas experiencias, situadas en esta línea de investigación, han permitido comprender la importancia de un factor capital en el nacimiento y evolución de la literatura durante el siglo XII. Me refiero concretamente al mecenazgo, en el preciso sentido que le ha concedido Joachim Bumke en una obra fundamental: Mäzene

1 Cfr. H.R. Jauss, Theorie der Gattungen und Literatur des Mittelalters, en Alierität und Modernität der mitielaluerticben Literatur, München, Fink, 1977; F. HEER, Aufgang Europas. Eine Studie zu den Zusammenbängen zwiscben politischer Religiositän. Frommigkeitsstil und dem Werden Europas im XII. Jahrbundert, Wien-Zurich, 1949. 
im Mittelalter ${ }^{2}$. Pero con anterioridad a esta reciente publicación el tema del mecenazgo fue planteado entre estudiosos germanistas y romanistas. Entre los «pioneros» sobresale Edward Schröder que en 1930 publicó un artículo sobte la figura de Rudolf Ems y su entorno literario, con la intención de fijar, a partir de un ejemplo concreto, el tipo de público al que iban dirigidas las obras literarias en la Edad Media. Este estudio surgió de la necesidad de relacionar el hecho literario con la sociedad y la política ${ }^{3}$, y puede entenderse como iniciador de una particular orientación en la investigación sobre la literatura medieval; sin embargo, habria de quedar aislado por mucho tiempo en el campo del germanismo.

Por su parte, los estudiosos de las literaturas románicas comenzaron a interesarse por esta perspectiva de análisis y, aunque muchos trabajos procedieran más de la fascinación por algunos personajes de la vida política del siglo XII que de una clara conciencia metodológica por situar la obra literaria en un contexto, hay que reconocer que se lograron algunos resultados dignos de destacar. Así, en 1954 Rita Lejeune publicó un estudio sobre el papel literario de Leonor de Aquitania ${ }^{4}$. Tratando de huir de la figura legendaria de Leonor forjada por Jos románticos, Mdme. Lejeune intentó demostrar el mecenazgo ejercido por la nieta del primer trovador entre los escritores de su época, especialmente desde su matrimonio con Enrique II Plantagenêt (1152) hasta su cautiverio (1173). Con tal fin, la estudiosa belga reunió diversos documentos (cartas, panegíricos, etc.) que presentaban a Leonor como una mujer de gran cultura interesada por las letras, así como todas las posibles referencias a la «reina de los ingleses» aparecidas en las obras de trovadores y romancier. De este modo, Leonor habría mantenido un contacto directo y personal con los escritores (des de Bernart de Ventadorn y con êl toda la generación de trovadores hasta el normando Wace), y las obras habrian surgido de

${ }^{2} \mathrm{~J}$. BUMKE, Mäzene im Mitrelalier. Die Gönner und Auftraggeber der höfischen Literatur in Deutschland, 1150-1300, München. Beck, 1979.

3 E. SCHRODFR, Rudolf von Ems und sein Literaturkseiss, en Zeitschrifi für dentsches Altertum und deutsche Literatur 67, 1930, donde consideró: ewo bleibt unsere alte litteraturgeschichte, wenn wir nicht ernstlich überall danach streben, sie mit der mittelalterlichen gesellschaft und ihren politischen trägern in die verbindung zu bringen die ihre existenzbedingung ausmache und ihr geschichtliches interesse trägt?» (p. 225).

4 R. LEjEUNE, aRôle littéraire d'Aliénor d'Aquitaine et de sa familles, en Cultura Neolatina 14, 1954, pp, 5-57. 
su impulso intelectual. En realidad, el mecenazgo de Leonor es planteado como un hecho obvio que no exige de un riguroso análisis de la documentación aportada como prueba demostrativas. En cambio, algunos años más tarde Rita Lejeune estudió el mecenazgo ejercido por los hijos de Leonor de un modo más sistemático, llegando a fijar con precisión algunas obras literarias surgidas en este entorno ${ }^{6}$. Ciertas dedicatorias en prólogos (como, por ejemplo, la del aCaballero de la carretas de Chrétien de Troyes a María, condesa de Champaña), algunos versos en poesías líricas en los que se exaltaba la liberalitas del príncipe (como, por ejemplo, los planbs de Bertran de Born o Gaucelm Faidit por las muertes del «joven rey Enriques o Ricardo) constituían pruebas reales de una eficaz protección a las letras por parte de algunos hijos de Leonor de Aquitania. Y, además, Rita Lejeune logró bosquejar una «geografia literarias en Francia, reconstruida, de modo fundamental, a través del itinerario de Leonor. En cualquier caso, la gran aportación de Mdme. Lejeune consistió en relacionar el quehacer literario del siglo XII con los intereses de una casa nobiliaria, dirigiendo así la atención hacia el tema crucial del mecenazgo.

Se imponía proseguir en este ámbito de investigación con estudios que lograran ahondar en la función desempeñada por los ambientes cultivados laicos en la expansión de la literatura occidental. Con esta intención, Reto R. Bezzola publicó en 1960 una extensa obra titulada Les origines et la formation de la littérature courtoise en Occident ${ }^{7}$. Según este autor, la expansión de la literatura cortés en el siglo XII fue posible gracias al impulso que príncipes y nobles ejercieron desde sus cortes, pero ésta no fue una conducta sin antecedentes, sino que tal hábito se fue forjando ya a partir del siglo V. De ahí que la obra de R. Bezzola no se limite al período de la literatura cortés, sino que vaya decididamente en

s Así, por ejemplo, afirma R. Lejeune, op. cit., p. 45: «a période littéraire des Plantagenêts, jusqu'à 1173, c'est donc principalement à Aliênor d'Aquitaine qu'on la doit. La preuve en est que lorsqu'elle disparaît momentanément de la scêne politique en 1173 , le mouvement de production littéraire se raréfie instantanément en Normandie comme en Angleterres.

6 R. LEJEUNE, «Rôle littéraire de la famille d'Aliénor d'Aquitaines, en Cabiers de civilisation médiévale 1, 1958, Pp. 319.337.

7 Reto R. BezzoLA, Les origines et la formation de la litsérature courtoise en Occident (500-1200). Premiêre partie, La tradition impériale de la fin de l'antiquité au XIè siècle, Deuxième Partie, La société féodale et la transformation de la littérature de cour (Tome I et II), Paris 1960 y publicado en Champion, 1966 1968. 
búsqueda de los «orígenes» con el fin de aRetracer dans la mesure du possible la vie intellectuelle et littéraire de ces cours depuis la fin de l'antiquité jusq'au XII siècle, tel est l'objet du premier volume que nous presentons aujourd'hui; dans le second nous nous attacherons à montrer comment, après cette période de preparation, une littérature vraiment nouvelle a pu se développer en France et en Angleterre grâce à une serie de circonstances particulièrement favorables $x^{8}$. En este extenso período de setecientos años, Bezzola considera la existencia de tres momentos particularmente significativos de la participación de la corte en el desarrollo literario. Se trata de tres períodos que coinciden con los tres renacimientos anteriores al italiano: carolingio, otoniano y anglonormando. De este modo, Bezzola considera una relación implícita entre los períodos en que tuvo lugar un renacer del mundo clásico y la intervención activa de los medios laicos en el desarrollo de la literatura. Así, la expansión literaria en las cortes del siglo XII se debe entender como el resultado de un lento proceso que culmina en los períodos carolingio y otoniano, en los cuales la cultura fue promovida por las capas elevadas de la sociedad. Esta especial circunstancia condujo a la creación de unas formas literarias que deben entenderse como el auténtico origen de los géneros que florecieron en el siglo XII ${ }^{9}$. En el proceso de la formación de la literatura cortés intervino también de forma directa la cultura eclesiástica, aunque la fusión entre el scaballeron y el «clérigon no tuviera lugar hasta el siglo XII ${ }^{10}$. Por ello, Bezzola debe considerar también los medios clericales, con el fin de valorar su aportación en la formación de la literatura cortés ${ }^{11}$.

8 Op. cit., Prèm. partie, p. IX.

9 Asi afirma Bezzola: aSans prétendre qu'il s'agisse là de filiation et d'influences directes, nous pouvons done affirmer de la façon la plus péremptoire, que les gentes destinés à jouer le rôle dècisif dans la littérature courtoise française et provençale au XII siècle, sont déjà ébauchés dans cette poésie latine des clercs. qui fleurit au X et XI, dans les cours épiscopales et dans les monastères* (Deux. partie, T.I., p. 139).

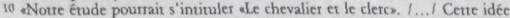
n'est pas nouvelle, mais il est bon, aujourd'hui peut-être plus que jamais, de la mettre en relief: une grande civilisation nait toujours quand l'action et la pensée, au lieu de produire deux classes d'hommes, deux castes, se fondent pour créer un idéal humain qui est la synthèse de deux aspirations, l'une et l'autre in. dispensables à ce que nous entendons par une personnalité complète. / ... / Le XIlé siècle ne nous eût-il donné que cette synthèse définitive qu'il serait par cela seul un des plus grands siècles de l'histoire européenes (Prém. partic, p. XXI).

11 Así, Bezzola, op. cit., afirma: «Prendre en considération des milieux 
La excesiva amplitud del campo de análisis impidió que el gran romanista suizo lograra responder con precisión a la pregunta inicial de su estudio: ¿cómo y en qué medida participaron los medios laicos en la formación de la literatura cortés? Esta dificultad fue subsanada por John F. Benton al ofrecer una dimensión microhistórica ${ }^{12}$ al tema de análisis. El estudioso norteamericano publicó en 1961 una investigación acerca de la corte de Champaña como centro literario ${ }^{13}$, logrando establecer cuatro grupos de escritores según sus diferentes relaciones con esta corte: 1 , autores que frecuentaban la corte; 2 , autores que escribieron para la corte; 3 , autores de cartas dirigidas al conde de Champaña; y 4, autores que escribieron acerca de la corte. De estos cuatro grupos, sólo los dos primeros pertenecieron al entorno cultural de Champaña y vivieron del mecenazgo de los condes. La diferenciación establecida por Benton despeja muchos errores, pues evita la usual confusión entre los autores que escribían para la corte y los autores que escribicron sobre la corte, lo cual no implicaba una dependencia directa con el condado. El estudio de Benton ha logrado ubicar con precisión los autores protegidos por María y el conde de Champaña, autores tales como Chrétien de Troyes, Gace Brulé o Gautier d'Arras y, en cambio, ha puesto en duda las relaciones entre otros autores y esta corte. Entre estos últimos, el caso más destacado sería el de Andreas Capellanus ${ }^{14}$.

cléricaux, et plus encore des couvents, dans une étude sur les origines et la formation de la littérature profane peut paraître au premier abord un peu étrange. Nous avons exposé plus haut les raisons qui nous ont induit à ne pas négliger ces milieux, surtout pour une époque où les cours des grands vassaux laíques n'avaient pas encore de rayonnement littéraire, mais où les grandes écoles épiscopales et conventuelles avaient déjà supplanté définitivement l'école du palais impérial ou royal. Le rapide examen de ces centres culturels cléricaux a montté le rôle éminent qu'ils jouèrent pendant les quatre siècles environ qui vont de la "renaissance carolingienne" à la "renaissance du XII siècle" (Deux. partie T. I. p. 129).

12 En el sentido que otorgó a este concepto J.E. Ruiz Doménec, «Microhistoria: de la etnografia al modelo regionals, en Atti del convegno storico internazionale per I'VIII centenario dell'urbanizzazione di Chiavari, Chiavari, 1980. pp. $473-487$.

13 J.F. BeNTON. \$The court of Champagne as a literary centers, en Speculum. vol. XXXVI, núm. 4. 1961, pp. 551-591. Acerea del mecenazgo cjercido en las cortes anglonormandas, ver también W.F. ScHIRMER. Die kulturelle Rolle des englischen Hofes im 12. Jabrbundert, en Studien zum literarischen Patronat im England des 12. Jabrbunderts, Köln u. Opladen, 1962, y D. LFGGE. Anglo. Norman Literatur and its Background, Oxford, 1963.

14 Cfr. J.F. Benton, op cit., p. 578. La ubicación de la obra de Andreas Cape. 
Todos estos estudios han planteado de un modo más o menos explícito el problema del mecenazgo medieval, pero no han conseguido valorar con rigor la importancia del fenómeno y su auténtica relación con la expansión de la literatura cortés. Se impone una rectificación de los objetivos de la investigación que, a mi modo de ver, sería posible supeditándola a los tres principios metodológicos siguientes: 1\% abandonando la preocupación por los corígenes» y situándonos en el momento de expansión (el siglo $\mathrm{XII}) ; 2^{\circ}$ centrándonos en una zona concreta y reconstruyendo de modo fidedigno la ageografía literarias; $3^{\circ}$. estableciendo la sociología del mecenazgo y fijando las causas que lo motivaron e hicieron posible. Se trata de una ingente tarea que exige de un planteamiento teórico coherente y de un profundo rigor en el análisis de toda la documentación disponible, pero lo cierto es que la citada obra de Joachim Bumke, Mäzene im Mittelalter, responde a estas cuestiones. Por ello, voy a llevar a cabo una exposición detenida de su contenido, en la idea de que esta obra debe considerarse además como un modelo de investigación para el tema que aquí nos ocupa: el mecenazgo y la literatura medieval.

La esfera de investigación de J. Bumke se limita a la literatura alemana de las cortes en los siglos XII y XIII. Este autor se propone demostrar que el mecenazgo hizo posible el nacimiento de la literatura en lengua vulgar, para lo cual ordena su análisis en tres dimensiones: 1 : establecer las premisas materiales y organizativas para la aparición del oficio regular de escritor en las grandes cortes laicas; 2 ? fijar $y$ analizar el tipo de documentación que permite

Hlanus en la corte de Champaña, había conducido a la mayor parte de criticos a relacionar el tratado De amore con el Chevalier de la charrete de Chrétien de Troyes, intentando además establecer una estrecha dependencia entre el tratado teórico y el roman. Siguiendo el estudio de A. Karnein, *Auf der Suche nach cinem Autor: Andreas, Verfasser von "De Amore" ', en Germanisch-romanische Monatscbrift, 1978, G. Duby situó a este escritor en el ambiente parisino de la corte real (en Les trois ordres ou l'imaginaire du féodalisme. Paris 1978, pp. 404 y ss.). Un estudio reciente ha demostrado que la ideología que se desprende de la obra de Andreas así como los presupuestos téricos en los que se basa, son ajenos al ambiente cultural de las cortes principescas y responde al modelo politico capeto: $c f r$. J.E. RUIZ DOMÉNEC, El juego del amor como re-presentación del mundo en Andrés el capellän. Bellaterra, Universidad Autónoma de Barcelona, 1980. 
asegurar la existencia del mecenazgo en las cortes laicas durante los siglos XII y XIII; 3a proporcionar una ksociología» del mecenazgo ${ }^{15}$. Pero antes de iniciar su estudio en estas tres dimensiones, J. Bumke revisa el material documental y bibliográfico, comprobando y poniendo de manifiesto que las fuentes no son ni muy abundantes ni muy ricas.

La investigación se ha visto constantemente dificultada por el persistente silencio de las crónicas y los Anales acerca del mecenazgo de reyes y príncipes; así, por ejemplo, Enrique II Plantagenêt aparece constantemente citado por sus coetáneos como un personaje ilustradísimo (litteratissimi, princeps eloquentissimus, litteris eruditis), pero en ningún caso se afirma de modo explícito que su corte fuera un centro literario, ni que el príncipe hubiera encargado obras a los escritores. Las noticias del mecenazgo se suelen encontrar en las propias obras literarias, en prólogos o epílogos, donde puede aparecer el nombre del autor acompañado del título de meister (magister) o de pfaffe (clericus) y, en ocasiones, también el nombre del que encargó la obra. Esto último se suele expresar con la fórmula mich bat (que no debe traducirse por ame rogós sino mejor por sme encargós ya que el verbo bîten poseía en la Edad Media un claro sentido de orden y obligación). Sin embargo, en muchísimos casos no consta el nombre del mecenas e incluso el autor se empeña en esconderlo con los medios más diversos como, por ejemplo, el acróstico. Naturalmente, debía tratarse de un ocultamiento artificial, pues el público al que iba dirigida la obra debía captarlo con facilidad, aunque a nosotros nos resulte en ocasiones difícil de vislumbrar. La escasez informativa de los documentos acerca del mecenazgo no indica que éste no existiera

$15 \mathrm{O}$ como el propio J. Bumke, op. cit. expresa en la "Introducción": «Das vorliegende Buch hat die Literatur der Fürstenhöfe im 12. und 13. Jahrhundert zum Gegenstand. Zunächst werden die materiellen und organisatorischen Voraussetzungen für die Entstehung eines geregelten Schriftbetriebs an den grossen weltlichen Höfen untersucht. Im Mittelpunkt stehen dann die unmittelbaren Zeugnisse für das literarische Patronat der Fürsten, wobei den Anfängen der höfischen Dichtung im 12. Jahrhundert besondere Wichtigkeit zugemessen wird. Die Gönnerverhalltnisse des 13. Jahrhunderts werden an Hand von Tannhäusers sechsten Leich erläutert, einem der interessantesten Texte dieser Zeit. Ein Kapitel ist der Rolle der Frauen im höfischen Literaturbetrieb gewidmet. Den Abschluss bildet der Versuch einer Soziologie der Mäzene und Auftraggeber im 13. Jahrhundert: es soll deutlich gemacht werden, welchen Anteil Könige, Fürsten, Grafen, Herren und Städte and der literarischen Entwicklung hattenx (p. 11). 
y que los autores escribieran por su propio impulso, sino que debe entenderse como lagunas que nos condenan a ignorar en qué cortes debieron elaborarse obras como el Parzival de Wolfram o el Tristan de Gottfried ${ }^{16}$.

Después de una atenta revisión bibliográfica sobre el tema, J. Bumke centra la orientación que debe asumir la investigación, considerando que la tarea más importante en el estudio del mecenazgo reside en comprender el significado de las distintas cortes y centros literarios, y el papel y función de aquellas que encargaban obras. En este sentido, la misión de la investigación sobre el mecenazgo ha de consistir en relacionar los inventarios literarios y la realidad histórica con el fin de que ambas facetas se iluminen a través de esa «puesta en relación». Y J. Bumke no duda en advertir y admitir que es ahí donde precisamente reside la gran dificultad $^{17}$, aunque hay que decir que es en ese terreno específico donde su investigación cobra mayor altura.

El estudio de las premisas materiales y organizativas que permitieron el oficio de escritor en las cortes de la segunda mitad del siglo XII -primera dimensión de análisis - constituye uno de los mejores hallazgos en el campo del medievalismo, tanto en el de la literatura como en el de la historia ${ }^{18}$. Bumke comienza por diferenciar corte imperial o monárquica (Königshof) de corte nobiliaria o principesca (Fürsten hof), precisando que la literatura se desarrolló en estas últimas cortes. De este modo, la creación de la literatura cortés (böfische Dichtung) y la nueva función de los príncipes como mecenas constituyen dos fenómenos inseparables, exigiếndose el análisis de la relación entre la evolución literaria y la realidad social ${ }^{19}$. Después de esta importante precisión, Bumke

16 Este análisis lo lleva a cabo J. Bumke, op. cit., en el primer capítulo eGönner und Auftraggeber: Quellen und Forschung», pp. 13-41), dividido en los sifuientes apartados: I. Gönnerverlusi and Gönnerwechsel, pp. 13.20, II. Das Quellenmaterial, pp. 21-32, III. Die Gönnerforscbung, pp. 33-41).

17 Cfr. J. Bumke, cit., p. 38: $\star$ Die Gönnerforschung steht vor der Aufgabe, literarische Befunde und historische Wirklichkeit zueinander in Beriehung zu setzen und wechselseitig zu erhellen; darin liegt die eigentliche Schwierigkeits.

18 Configura el segundo capitulo: «Das Fürstenhof als literarisches Zentrum», pp. 42-72, dividido en los siguientes apartados: 1. Mïndliche Traditionen, pp. 42-43. II. Hauskloster und Fürstenbof, pp. 44-53, III. Zum Begriff adelshitenaturn pp. 54-57, IV. Residenzen und Kanzlezen, pp. 58-64, V. Das lisenariscbe Interesse der Fürsten, pp. 65-67, VI. Die gesellscbaftliche Stellung der Dichter, pp. 68-72.

19 Asi lo expresa J. Bumke, op, cit. p. 42: «Bis zum 12. Jahrhundert war der 
no puede admitir la tesis de Karl Hauck acerca de la existencia de una literatura nobiliaria desde el siglo IX, pues sólo a mediados del siglo XII se dieron las condiciones necesarias para que la nobleza asumiera la función del mecenazgo. Una vez más, la discrepancia es de orden histórico y nos conduce al problema de la formación de la nobleza en la Edad Media ${ }^{20}$.

Aun cuando Bumke sitúe la corte nobiliaria como centro literario a mediados del siglo XII, el autor no niega la existencia de una literatura de tradición oral fomentada entre los señores feudales; una literatura que suponemos de tipo heroico (Heldendichtung) y cuya historia yace en la oscuridad ${ }^{21}$. Este tipo de literatura oral debió contribuir a forjar la imagen que de sí misma pretendía imponer la aristocracia. Pero las ansias de autorrepresentación de las clases sociales elevadas comenzaron a verse realmente colmadas en

Königshof der wichtigste Ort der Literatur ausserhalb der Klöster und Stifte. Wenn man unter Literatur den Gesamtbereich der schriftlichen Betätigung versteht wenn man die lateinische Geschichtsschreibung und alle Wissenschaften einbezieht, hat der Königshof auch in der Zeit um 1200 noch eine führende Rolle gespielt. Fasst man jedoch nur den engeren Bereich der damals neu entstan. denden höfischen Dichtung ins Auge, dann ist die literarische Aktivität der Kö. nige von der ihrer grossen Kronvasallen nicht mehr zu unterscheiden, ja sie tritt, aufs Ganze gesehen, dahinter zurück. /.../ Die Entfaltung der höfischen Dichtung und die neue Rolle der Fürsten als Gönner und Auftraggeber sind nicht voneinander zu trennen: der Zusammenhang zwischen literarischer und gesellschaftlicher Entwicklung ist hier offenkundig*.

20 La crítica a la tesis de Karl Hauck la expresa J. Bumke, cit, del siguiente modo: Der Begriff Adelsliteratur, wie Hauck ihn gebraucht hat, ist allerdings so weit gefasst dass er alle literarischen Erscheinungen im Bereich der weltlichen Oberschichten umgreift und auch die Literatur des Kaiserhofes mit einschliesst. So war für Hauck die Rolle, die der Hof Kaiser Heinrichs III. im literarischen Leben des 11. Jahrhunderts gespielt hat, von grundlegender Bedeutung für das Verständnis von Adelsliteratur in dieser Zeits, afirmando más adelante eHaucks Thesen führen auf das Problem der Laienbildung im Mittelalter» p. 54. Para el problema de la formación de la nobleza, cfr. la edición de T. REUTFR, The me. dieval nobility, North Holland 1979, donde se encuentra el estudio de KARL HAUCK. The literature of house and kindred associated with medieval noble fa. milies, illustrated from eleventh-and rwelfth century satires on the nobilitys; en este artículo expuso Hauck la teoría rebatida por J. Bumke.

${ }_{21}$ Ello constituiría la eprehistorias del mecenazgo: «Das Mäzenatentum der Fürsten hat eine lange Vorgeschichte die bis in die germanische Stammeszeit zurückzicht. Alles, was der höfische Dichtung zeiclich vorausgeht, gehört in den grossen Bereich mündlicher Uberlieferungen und liegt für uns zum grössten Teil in einem undurchdringlichen Dunkel. Wir wissen aus historischen Quellen, dass an den Höfen des hohen Adels Heldenlieder gesungen wurdens, \{cfr. $\}$. Bumke, cit., p. 43). 
las formas escritas que les ofreció el monasterio. Resulta difícil precisar la fecha en que este centro cultural entró en contacto directo con el mundo laico. Existen grandes diferencias regionales, pero es posible establecer tres fases en la relación centro monástico/centro laico: en una primera fase, la aristocracia apareció en las crónicas de fundadores (Stifterchronik); en una segunda fase, los monasterios se ocuparon de trazar la historia genealógica de algunas familias; en una tercera fase, el quehacer literario se desprendió del monasterio y se instaló en la corte. Esta tercera fase coincidió con la expansión de la literatura cortés ${ }^{22}$. Hay que distinguir los libros de fundaciones de las historias genealógicas, pues estos primeros no indican el camino hacia el florecimiento de la literatura. En cambio, existe una estrecha relación entre la historia genealógica y la expansión literaria de las cortes, pues en aquella primera literatura latina la aristocracia recibió por vez primera una configuración representativa. Es importante tener en cuenta que las mismas familias que recibieron un tratamiento genealógico por parte de los monjes, aparecieron luego como mecenas de la literatura cortés, y que la literatura genealógica se desarrolló en zonas geográficas que pocos años más tarde habrían de adquirir un sig. nificado especial en el florecimiento de obras en lengua vulgar. Así, si en Flandes, Lambert de Ardres elabora su Historia comitum Ghisnensium, en el sur de Alemania se construye la Historia Welforum, surgida concretamente en los monasterios güelfos de Altdorf-Weingarten, Steingaden, Rottenbuch y Altmünster ${ }^{23}$.

El proceso de feudalización, que se manifestó en una abierta usurpación del poder político y en la constitución de señoríos territoriales, condujo en un período de madurez a la creación de un modelo imaginario que recogiera sus aspiraciones y en el que se reafirmara su propia existencia. La sociedad del noroeste de Fran-

22 J. Bumke, cit., pp. 44-53, toma esta periodización en tres fases del estudio de H. Patze, ${ }^{A} \mathrm{Adel}$ und Stifterchronik. Frühformen territorialer Geschichtsschreibung im hochmittelalterlichen Reichs, en Bläter fïr deutsche Landesgeschicbie 100, 1964, pp. 8-81; 101, 1965, pp. 67-128.

${ }^{23} \mathrm{Cfr}$. J. Bumke, cit., p. S1: Für unseren Zusammenhang ist das Entscheidende, dass dieselben Fürsten und Fürstenhäuser, deren Fammilienüberlieferung sich in solchen Genealogien niederschlagen hat, als Gönner und Auftraggeber der höfischen Dichtung wiederbegegnens. La importancia de la literatura genealógica para el análisis de las *mentalidades* de la aristocracia laica ya fue puesta de manifiesto por G. DUBY, aObservaciones sobre la literatura genealógica en Francia en los siglos XI y XIls en Hombres y estructuras de la Edad Media, Madrid, Siglo XXI, 1977, pp. 184-197. 
cia configuró a través de la literatura cortés sus propios ideales (caballería y amor); el ejemplo francés se difundió también en Alemania y los príncipes se interesaron por promover aquella literatura concebida como un atributo de poder y utilizada para sus intereses de legitimación ${ }^{24}$. Pero el fomento de esta literatura, donde las clases sociales elevadas se vieron autorrepresentadas, coincidió por un lado, con una fase de estrecha relación entre la cultura escrita que le proporcionaban los monasterios y la propia evolución interna de esta sociedad, $y$, por otro, con el desarrollo de dos elementos de organización material de la sociedad: la residencia y la cancillería. Durante el siglo XII las residencias nobiliarias sufrieron importantes transformaciones. Los nuevos palacios aumentaron considerablemente sus dimensiones y recibieron una mayor ornamentación en columnas, capiteles y arcadas. Esta transformación arquitectónica, que atendió fundamentalmente a la necesidad de ampliar el espacio, permitió la conversión de la residencia en una auténtica corte. Se originó así un espacio capaz de asumir un público con intereses literarios y en el que se pudo desarrollar la nueva forma de vida acortés». El nuevo espacio cortesano acogió la «práctica de la escritura» que hasta el momento se había encontrado recluida en los centros monásticos. La aparición de algunas cancillerías en las cortes de los príncipes creó un hábito regular de escritura, sin el cual dificilmente habría sido posible el nacimiento

${ }^{24}$ Cfr. J. Bumke, cit., p. 68: «Dic Gründe für die persönliche Betroffenheit und die aussergewöhnliche literarische Aktivität des hohen Adels sind nicht schwer zu erkennen. Die Sorten von Literatur, die schon jahrhundertlang Gegenstand eines königlichen Mäzenatentums gewesen waren, hatten die gesellschaftlichen und künstlerischen Interessen der Auftraggeber kaum jemals so unmittelbar ansprechen können, wie das der neuen höfischen Dichtung gelang, in det etwas zur Darstellung kam, was offenbar für die adligen Herren höchste Aktualität besass: nämlich die moderne französische Gesellschaftskultur, die man an den eigenen Höfen zu verwirklichen trachtete, und die neuen ldeale von Ritterschaft und Minne, denen man zwar sicher nicht im Alltag, aber in den festlichen Stunden höfischer Geselligkeit nachzufeiern begann und in denen man eine Idee adliger Vollkommenheit ausgesprochen fand, die in allen wichtigen Punkten als eine Bestärigung der eigenen Existenz und der eigenen Bestrebungen aufgefasst werden konntes. Un análisis de los sistemas de valores de la nobleza en Alemania, of, en K. Bosl, aLeitbilder und Wertvorstellungen des Adels von der Merowingerzeit bis zur Höhe der feudalen Gesellschafts, en H. Scholler. The Epic in Medieval Society. Tübingen, Max Niemeyer, 1977, pp. 18-35. Bumke sigue a Bosl en la teoría de que la alta nobleza se configuró re-presentativamente en la obra literaria de la segunda mitad del siglo XII (cfr. K. Bosl, op. cit., pp. 21 y ss.). 
de la literatura en lengua vulgar en estos nuevos centros de cultura ${ }^{25}$

Así pues, Joachim Bumke entiende la aparición de la literatura de corte como resultado de diversos factores que confluyeron a mediados del siglo XII: en primer lugar, las características de la propia sociedad feudal en su período de madurez; en segundo lugar, se advierte un factor de orden ideológico surgido de las ansias de autorrepresentación de esta sociedad; en tercer lugar, intervinieron dos factores de orden material y organizativo, tales como la transformación arquitectónica de las residencias nobiliarias y la introducción de la cancillería en las cortes, fenómeno que implica ya la independencia cultural del espacio laico con respecto al espacio monástico. Esta circunstancia política, social, ideológica y material tuvo lugar a mediados del siglo XII y coincidió con la aparición de obras literarias escritas en lengua vulgar. Sin embargo, la conjunción de todos estos factores no habría hecho florecer la literatura de corte si no hubiera existido el mecenazgo de los príncipes.

En una segunda dimensión de análisis, Bumke se propone demostrar el mecenazgo ejercido por algunas cortes principescas de Alemania en la segunda mitad del siglo XII. Para ello, recurre a las propias obras literarias surgidas en este período, no $\sin$ antes fijar una necesaria diferenciación entre lo que él denomina literatura de corte (Hofliteratur) y literatura cortés (böfische Literatur). De este modo solventa la difícil clasificación literaria de las obras con las que se enfrenta, para dar paso a una clasificación sociológica, pues bajo el concepto Hofliteratur agrupará todas aquellas obras surgidas en la corte, ya presenten o no, temas que la crítica ha acostumbrado a interpretar como ecorteses ${ }^{26}$. Partiendo de una distinción por géneros, Bumke intenta situar las distintas

25 Cfr. J. Bumke, cit., p. 61: *In diesem Sinne kann man das Aufblühen der Dichtung mit der Weiträumigkeit der neuen fürstlichen Residenzen in direkte Verbindung bringens, y p. 63: «Mit dem Aufbau eigener Kanzleien an den Hofen der weltlichen Fürsten im 12. Jarhundert begann auch dort eine geregelte Schriftlichkeits.

${ }^{26} \mathrm{El}$ análisis del mecenazgo en el siglo XII aparece desarrollado en el capítulo tercero: «Die Anfänge der höfischen Dichtung. Gönner und Höfe im 12. Jahrhunderts, pp. 73-175, dividido en los siguientes apartados: 1 . Hofliteratur und böfische Literatur, pp. 73-75, II. Weltliche Ep ik pp. 75-124, 11I. Minnesang und Spruchdichtung, pp. 124-134. IV. Weitere Gönnerzeugnisse des 12. Jahrhunderts, pP. 134-137, V. Welfische oder staufische Dicbiung?, pP. 137-154, VI. Höfe und Gönner an Ende des 12. Jarhunderts, pp. 154-175. 
obras dentro de la geografia alemana. Entre las obras pertenecientes a la epopeya (welthiche Epik, incluyendo el concepto tanto cantares de gesta como romans) tan sólo en dos se reconoce el mecenazgo y se cita al personaje que ha encargado la obra: el $p$ faffe Konrad del Rolandslied cita a un tal Hainrichs que tras un minucioso análisis es identificado con Enrique el León; por su parte, Heinrich von Veldeke dirige su Eneit a la condesa de Kleve. De ello deduce Bumke que la nueva literatura encontró protección en las cortes de los príncipes más poderosos: en la corte bávara de Enrique el León en Regensburg y en la corte turingia de Ludwig III (esposo de la condesa de Kleve), debiendo ser éstos los primeros centros literarios en Alemania ${ }^{27}$. En lo que respecta a la lírica cortés de tema amoroso (Minnesang) se advierte la casi total inexistencia de noticias de mecenazgo, lo que debe venir determinado porque este ámbito literario fue ejercido por los propios señores y príncipes. En cualquier caso parece que el auténtico centro de la poesía lírica a finales del siglo XII debió encontrarse en la zona suroccidental, en el entorno de la corte imperial y en la corte de la familia Babenberg; por el contrario, la literatura gnómica (Spruchdichtung) no se limitó a las grandes cortes principescas sino que debió encontrar interés en círculos más amplios de la alta nobleza. La literatura didáctica en lengua vulgar rambién fue fomentada en las corres laicas, destacando entre ellas Braunschweig que se encontraba bajo el dominio de Enrique el León ${ }^{28}$. En este punto de su investigaciôn, Joachim Bumke advierte la necesidad de tomar partido por una antigua cuestión suscitada entre los germanistas: lla literatura de corte está ligada al poder de los Welfen o al de los Staufen? O según se había planteado: ¿el entorno de los Welfen produjo un tipo de literatura diferente en cuanto estilo y temática a la literatura surgida del ambiente Staufen?29. De

27 Die weltiche Epik des 12. Jahrhunderts war in Bayern, im Rheinland und in Thüringen konzentriert» ( $c f r$. J. Bumke, cit., p. 120). A esta conclusión llega J. Bumke después de una minuciosa tevisión de las siguientes obras: el Alexanderlied de Lamprecht, la Kaisercbronik, el Rolandslied de Konrad, König Rother, Herzog Emst, el Reinhart Fucbs de Heinrich der Glichesaere, el Strassburger Alexander, el Trierer Flayris, Graf Rudolf, el Tristrant de Filhart von Oberge y el Eneit de Heinnich von Veldeke.

28 Cfr. Bumke, cit., pp. 124-134. Bajo el mecenazgo de Enrique el León se realizó el Lucidarium, compendio de ciencia teológica y cosmológica, redactada por su capellán de la corte de Braunschweig.

29 Tal era la teoría de H. Naumann, «Kurzer Versuch über welfische und staufische Dichtung*, en Elsass-Lothringisches Jabrbuch 8 1929, pp. 69-91. 
nuevo, Bumke orienta la cuestión desde una perspectiva sociológica y la plantea del siguiente modo: ¿qué influencia ejercieron ambas casas nobiliarias en la evolución literaria del siglo XII, es decir, cuál fue el significado de estas cortes en el quehacer literario? ${ }^{30}$. Según este autor, la nueva literatura de corte surgió en los dominios de los Welfen (en Regensburg, Altdorf-Weingarten y Braunschweig), constituyendo estas cortes los primeros puntos de reunión de una literatura laica nacida de los modelos franceses. En cambio, sólo es posible hablar de literatura de los Staufen en un sentido cronológico, cuando se hace referencia a la literatura de la época de la casa Staufen. Bajo Federico I y Enrique IV la corte imperial fue un centro significativo para la producción historiográfica y también para la poesía latina. Pero nada permite asegurar que Federico I hubiera participado en la vida literaria ni que hubiera ejercido mecenazgo. Walther von der Vogelweide fue el primer poeta que compuso para la casa de los Staufen en el año $1198^{31}$.

Así, es posible concluir que la literatura de corte se originó de la iniciativa de las casas nobiliarias más poderosas y concretamente en el ambiente de los Welfen. Ya Welf VI debió de rodearse de escritores a juzgar por las noticias que nos proporciona la Historia Welforum, y esta casa debió de haber ejercido una intensa labor literaria hasta la muerte de Enrique el León en el año 1195; el otro gran centro literario lo encontramos en el ambiente de la familia Ludowinger, desde Ludwig III y su esposa Margarete von Kleve hasta su hijo Hermann de Turingia ${ }^{32}$.

El estudio del mecenazgo durante el siglo XIII se encuentra fa-

$30 \mathrm{~J}$. Bumke, cit., plantea en estos términos la cuestión: \&Wenn hier die Frage nach der Wichtigkeit der Begriffe "welfisch" und "staufisch" für die Literaturgeschichte noch einmal aufgegriffen wird, so geschicht das in dem Bestreben. diesen Begriffen wieder einen möglichst genauen historischen Sinn zu geben. Das kann am ehesten erreicht werden, wenn man fragt, welchen Einfluss die beiden Herrscherhäuser auf die literarische Bedeutung ihren Höfen im Literaturbetrieb der Zeit zugekommen isto (p. 138).

31 Con todo, J. Bumke, cit. indica: sFür die Ausbildung der volkssprachigen Literatur hat er allenfalls im Bereich des Minnesangs eine wichtige Rolle gespielt. (Se refiere a Federico I) Wenn man es jedoch für wahrscheinlich halten kann. dass die Lyriker um Friedrich von Hausen ihr Zentrum in Italien hatten, dann gibt es kaum einen deutsehen Text des ausgehenden 12. Jahrhunderts, der seine Entstehung dem literarischen Patronat des staufischen Kaiserhofs verdankt» (p. 154).

32 En el sexto apartado de este capítulo tercero (pp. 154-175) J. Bumke establece con precisión todos los mecenas conocidos de la segunda mitad del siglo XII, reconstruyendo la ageografia literaria». 
cilitado por la existencia de un documento de gran riqueza. Se trata del sexto Leich h33 de Tannhäuser, donde el poeta llevó a cabo una alabanza a los príncipes. Este poema debió de componerse entre los años 1256 y 1266 y en él aparecen enumerados los grandes mecenas del pasado y de la época de Tannhäuser. Consideran. do la estructura del poema, Bumke lo divide en dos partes separadas por la pregunta wer erbet nur ir milte? (¿quién hereda su generosidad?) En la primera parte, el poeta hace referencia a los príncipes que ejercieron mecenazgo según le ha sido transmitido por la tradición literaria, mientras que dedica la segunda parte a los grandes mecenas de su tiempo, posiblemente a aquellos con los que mantuvo contacto. Además de constituir una auténtica guía de los centros literarios del siglo X\II, el Leich revela un rasgo peculiar de gran importancia para la evolución del mecenazgo medieval: mientras que los mecenas citados en la primera parte proceden de modo indistinto de casas nobiliarias, los mecenas de la segunda parte (es decir, los del siglo XIII) sólo se situan en los principados imperiales. La liberalitas de los nobles de finales del siglo XII fue heredada por las cortes imperiales del siglo XIII ${ }^{34}$.

La mujer también desempeñó un importante papel como mecenas en el panorama literario alemán de la segunda mitad del siglo XII. Se conocen con seguridad algunos personajes significativos para la evolución de la literatura de corte, como por ejemplo Mathilde de Sajonia, Agnes de Loon, Margarete de Kleve, pero la situación documental impide valorar con precisión su

33 Leich: composición lírica construida a base de estrofas desiguales.

34 El VI Leich de Tannhäuser había sido comúnmente entendido por la crítica como una obra de carácter marcadamente biográfico. J. Bumke logra transformar esta difundida opinión en el completo y agudo análisis del poema en el cuarto capítulo: बTannhäusers sechster Leich. Die fürstlichen Gönner des 13. Jahrhunderts", pp. 176-230, dividido en los apartados: I. Beschreibung des Textes, pp. 176-179, II. Der historische Hintergrund, pp. 179-186, III. Die Gönner der al. ten Ziti, pp. 186-190, IV. Die fürstlichen Gönner der Gegenwart, pp. 191-229, V. Ausblick, pp. 229-230. El análisis del Leich le permite concluir: «Tannhäusers Fürstenleich ist ein Wegweiser zu den literarischen Zentren des 13. Jahrhunderts. I... / Uberschaut man noch einmal die Namen, die Tannhâuser genannt hat, dann fallt wohl am meisten auf, dass in der zweiten Gönnerreihe fast ausschliesslich Reichfürsten vorkommen. /.../ Es ist nicht anzunehmen, das Tannhäuser es sich zum Prinzip gemacht hätte, nur Gönner fürstlichen Ranges aufzuführen. Denn unter Gönnern der alten Zeit sind mit den Namen Abenberg, Tübingen, Landsberg und Katzenelnbogen eine ganze Reihe gräflicher Familien genannt* (p. 229). 
influencia ${ }^{35}$. En cambio, la revisión de todo el material documental ha permitido a Joachim Bumke establecer la sociología del mecenazgo en los siglos XII y XIII. En esta tercera dimensión de análisis encontramos uno de los mayores logros de su estudio, pues se extraerán conclusiones fundamentales para la comprensión del fenómeno literario medieval ${ }^{36}$.

Bumke ha fijado los grupos sociales que con su mecenazgo participaron en el florecimiento y la expansión de la literatura de corte alemana en los siglos XII y XIII:

a) los condes: las casas condales desempeñaron un papel crucial en los comienzos de la literatura de corte; así lo atestiguan los condados de Loon y Kleve, donde Heinrich von Veldeke encontró a sus primeros mecenas. Pero en épocas sucesivas los testimonios de mecenazgo en casas condales comienzan a escasear.

b) Los príncipes: el Leich de Tannhäuser no deja lugar a dudas de la función desempeñada por las cortes de los grandes señorios territoriales.

c) Emperadores y reyes: en el siglo XIII abundan los testimonios de mecenazgo ejercido por emperadores y reyes. El caso más patente es el de Federico II de Sicilia y de sus hijos Heinrich y Konrad.

d) Obispos: sería necesario profundizar en la relación entre el mundo eclesiástico y el mundo laico para la elaboración literaria en lengua vulgar, en especial, en lo que respecta a la poesía heroica. No hay duda del mecenazgo eclesiástico para la poesía latina (en concreto, la de los Vaganten) y tampoco que el obispo de Strassburg, Konrad von Lichtenberg, fue uno de los grandes protectores de la literatura entre 1273 y 1299.

e) Las ciudades: también constituyeron centros literarios, sobre todo, las ciudades obispales donde, junto a la catedral, se encontraba la cancillería, la escuela y bibliotecas. Basilea, Constanza y

$35 \mathrm{~J}$. Bumke, cit., dedica un quinto capítulo a analizar la función de la mujer como mecenas: *Die Rolle der Frau im Hófischen Literaturbetriebs, pp. 231247. dividido en los apartados: 1. Religiöse Litenatur im 12. Jabrbundert, pp. 231-232 y II. Höfusche Litenatur, pp. 233-247.

36 Este es el objetivo del capítulo sexto: « Versuch einer Soziologie der Gönner und Auftraggeber im 13. Jahrhunderts, pp. 248-293, que offece los siguientes apartados: 1. Kaiser und Könige, pp. 248-252, II. Weltliche Fürsten, pp. 253255, III. Bischöfe und geistliche Wirdentrager, pp, 256-264, IV. Grafen, pp. 265-271, V. Freiherren und Ministerialen, pp. 272-282, VI. Stälien, pp. $283-$ 293. 
Zürich fueron las primeras ciudades en las que floreció una literatura de corte. Un tipo de literatura que no debe calificarse como «burguesa», ya que respondió a los intereses de los grupos sociales elevados, protegiéndose así un estilo conservador, tanto en la épica como en la lírica.

Finalmente, Bumke plantea la posible participación de los ministeriales en la producción literaria. La difundida teoría según la cual la literatura de corte habría nacido en las pequeñas residencias de caballeros y ministeriales resulta, según este autor, totalmente injustificada y carente de argumentos ${ }^{37}$. En efecto, cada vez son más raras las noticias de mecenazgo cuanto más se desciende de la pirámide feudal; en ocasiones, aparecen citados personajes procedentes de la ministerialidad. Así ocurre con Heinrich von Rispach mencionado en el Parzival de Wolfram, pero la cita no contiene ningún rasgo que caracterice como mecenas a este personaje y más bien debe entenderse como una alusión a alguien que pertenecía al público al que iba dirigida la obra. Posiblemente, a finales del siglo XIII, algunas pequeñas residencias nobiliarias o incluso ministeriales se interesaron por la literatura, ofreciendo cierta protección a algunos escritores, pero en ningún caso debe incluirse este grupo social entre los auténticos mecenas de la literatura de corte.

El tema del mecenazgo ha logrado iluminar el conjunto de elementos que hicieron posible el nacimiento y expansión de la literatura de corte, deduciéndose del estudio de Joachim Bumke las siguientes conclusiones generales:

1. Durante la segunda mitad del siglo XII, la literatura de corte surgió bajo el mecenazgo ejercido por los grupos sociales elevados (las casas nobiliarias).

2. El mecenazgo literario fue posible gracias a la aparición de un nuevo espacio, la corte, y a la introducción de la cancillería en los centros laicos, regularizándose el oficio de escritura.

3. Los grupos sociales elevados asumieron la función del mece-

37 En este punto J. Bumke, cit., se muestra taxativo: «lm übrigen wird man sagen können, dass gegen Ende des 13. Jahrhunderts die kleineren Adelssitze einen nicht unbeträchtlichen Anteil an der Pflege und Tradierung der Ritterdichtung hatten. Aber von der noch immer weit verbreiteten Vorstellung, dass die höfische Literatur schon seit ihren Anfängen in der Hauptsache auf den Burgen und an den kleinen Höfen von Rittern und Ministerialen geblüht habe, sollten wir Abschied nehmen* (p. 283). 
nazgo literario por una necesidad de ver configuradas en las obras literarias su realidad y sus aspiraciones.

4. A partir del año 1200 aproximadamente se observa una traslación del mecenazgo de las casas nobiliarias hacia las cortes imperiales.

5. En la sociología del mecenazgo habría que llegar a establecer el papel ejercido por el mundo eclesiástico, en especial, por los obispos $^{38}$.

En Mäzene in Mittelalter se ha descrito con precisión el panorama del mecenazgo en Alemania a lo largo de ciento cincuenta años. Su aportación al tema de la literatura medieval y el mecenazgo puede ser condensada en tres puntos fundamentales: 1) la demostración de la existencia de ese mecenazgo; 2) la identificación de los mecenas con los personajes históricos de la época y 3) la sociología del mecenazgo. Pero esto no es todo. Al inicio de su estudio, Joachim Bumke afirmaba: «El arte medieval era arte de encargo y así debe ser entendido ${ }^{39}$; y esta realidad le conducía a explicar uno de los grandes enigmas de la literatura medieval: el carácter inacabado de la mayor parte de obras de los siglos XII y XIII. Según Bumke, la pérdida del mecenas debió ser la causa de que muchos escritores no terminaran sus obras ${ }^{40}$. Sin embargo, esta relación de causa a efecto entre una pura condición material y el «misterio» que encierra una obra literaria puede conducir a error. La sociología de la literatura, tal y como se muestra ejemplificada en el estudio de Bumke, resulta valiosísima para la reconstrucción de una circunstancia, pero no logra una explicación de aspectos de las obras literarias, pues llega a caer en planteamientos reduccionistas. El hecho de que un escritor no termine su obra puede deberse a múltiples factores y sólo el análisis hermenéutico de la propia obra lograría responder a tan compleja cuestión. Asimismo, una perspectiva sociológica del análisis está incapacitada para determinar los componentes ideológicos y utópicos que se configu-

38 La obra de J. Bumke se completa con un rico apéndice de los textos urilizados como prueba del mecenazgo: Texte, Die Gönnerzeugnisse der höfischen Li teratur im 12. und 13. Jahrbundert, pp. 455-669.

39 Cfr. Bumke, cit., p. 9: ^Mittelalterliche Kunst war Auftragkunst und muss so verstanden werdens.

40 Precisamente ese carácrer propio de la obra literariz en la Edad Media parece dar pie al estudio de J. Bumke, cfr. cap. I, I: Gönnerverlust und Gönnerwech. sel, pp. 13-21. 
ran en una determinada obra. En cambio, la historia social ofrece suficiente dimensión teórica para desvelar lo imaginario que se esconde tras la ficción literaria. Esta es la gran distancia que separa, teórica y metodológicamente a la historia social aplicada al análisis literario y a la sociología de la literatura ${ }^{41}$. Los análisis orientados desde la disciplina de la historia social deberían responder a una cuestión fundamental que se suscita del tema acerca de la relación entre el mecenazgo y la literatura medieval y que se podría plantear del siguiente modo: ¿a qué grupo social corresponde la ideología que se configura en la literatura de corte de la segunda mitad del siglo XIl y hasta qué punto los grupos sociales elevados se independizaron ideológicamente de los centros eclesiásticos, configuradores hasta aquel momento de su propia imagen? ${ }^{42}$. En cualquier caso, una clara conciencia de los límites en la esfera de la investigación de ambas disciplinas (historia social y sociología de la literatura) podría permitir un productivo encuentro y confrontamiento de los resultados obtenidos.

41 Cfr. J.E. Ruiz Doménec, «Littérature et Société médiévale: vision d'ensembles, en Le Moyen Age, núm. 1, 1982, pp. 77-114.

42 Así, por ejemplo, piensa J.E. Ruiz Doménec, opp. cit., p. 108: «Ainsi, la divergence de vue avec le professeur $\mathrm{E}$. Köhler repose sur le fait que si, pour lui, l'assise objective s'établit d'une manière dialectique uniquement avec un groupe social réel, pour nous, elle peut le faire avec un groupe social imaginaire. L'oeuvre littéraire ne sérait rien d'autre que la mise en pratique, au sein d'une société, des relations de force qui se produisent dans la sphère imaginaire. Par exemple, au XIIé siècle, entre l'aristocratic lä̈que et I'Eglises. Ello ha sido comprobado por este mismo autor en dos estudios sobre la obra de Chrétien de Troyes, cfr. J.E. Ruiz Doménec, El laberinto cortesano de la caballeria, 1. El juego como estructura de identidad en ale Chevalier de la charretes de Chrétien de Troyes (monografias 1 *Medievalias, Bellaterra, 1981) y 2. La diferencia como $t i$ mite exterior del juego en el *Chevalier au lion" de Chrétien de Troyes (monografias 2. «Medievalia», Bellaterra 1982). 